Article

\title{
Effect of Functional Polycarboxylic Acid Superplasticizers on Mechanical and Rheological Properties of Cement Paste and Mortar
}

\author{
Wuju Xun ${ }^{1}$, Changlong $\mathrm{Wu}^{2}{ }^{2}$, Jiye $\mathrm{Li}^{3}{ }^{3}$, Chengwu Yang ${ }^{2}$, Xuefei Leng ${ }^{1}$, Desheng $\mathrm{Xin}^{2}$ \\ and Yang $\mathrm{Li}^{1 \text {,* }}$ \\ 1 State Key Laboratory of Fine Chemicals, Liaoning Key Laboratory of Polymer Science and Engineering, \\ Department of Polymer Science and Engineering, School of Chemical Engineering, \\ Dalian University of Technology, Dalian 116024, China; liyaxun123er@163.com (W.X.); \\ lengxuefei@dlut.edu.cn (X.L.) \\ 2 Dalian Research \& Design Institute of Building Science Stock Co., Ltd., Dalian 116021, China; \\ dljkywcl@163.com (C.W.); dljkyyangchengwu@163.com (C.Y.); dljkyxds@163.com (D.X.) \\ 3 College of Civil Engineering, Dalian Minzu University, Dalian 116650, China; jiyeli@dlnu.edu.cn \\ * Correspondence: liyang@dlut.edu.cn; Tel.: +86-1370-009-8600
}

Received: 15 July 2020; Accepted: 4 August 2020; Published: 5 August 2020

Featured Application: The polycarboxylic acid-based high-performance water-reducing agent products provided in this article can be used in high-strength and high-performance concrete, such as bridges, high-rise buildings, high-speed railways, nuclear power plants, hydropower stations, etc., which can improve the working performance, mechanical properties, and durability of concrete and extend the service life of buildings.

\begin{abstract}
Modern engineering practices require that polycarboxylic acid high-performance superplasticizers have good adaptability to various environments and materials, which indicates the importance of producing functional polycarboxylic acid superplasticizers with a variety of functions. Therefore, in this work, a functional polycarboxylic acid high-performance water-reducing agent, named superplasticizer J, a sustained-release functional polycarboxylic acid high-performance water-reducing agent, named superplasticizer $\mathrm{H}$, and an early-strength functional polycarboxylic acid high-performance water-reducing agent, named superplasticizer $Z$, are synthesized. The produced superplasticizers were characterized by employing X-ray diffraction (XRD), thermogravimetry, mercury intrusion porosimetry, and rheometry and by measuring heat of cement hydration. The impacts of the functional polycarboxylic acid superplasticizers on the mechanical properties, rheological properties, and cement hydration of the cement pastes and mortars were investigated. The results show that the prepared functional polycarboxylic acid superplasticizers fulfill water-reducing and cement dispersion functions, can improve the fluidity and plasticity of the mortar, and have a greater effect on reducing shear yield stress and increasing plastic viscosity compared to the naphthalene-based superplasticizers. The sustained-release functional polycarboxylic acid high-performance superplasticizer $\mathrm{H}$ performs an excellent slump retention function, and the early-strength functional polycarboxylic acid high-performance superplasticizer $\mathrm{Z}$ has a significant effect on improving the early and late strength of the mortar.
\end{abstract}

Keywords: functional superplasticizer; polycarboxylic acid high-performance water-reducing agent; rheological property; heat of cement hydration; XRD; thermogravimetric 


\section{Introduction}

The high durability and long life of concrete structure can significantly reduce the cost and environmental impact, which is the trend and hotspot of international concrete research [1]. Polycarboxylic acid water-reducing agent is considered to be the third breakthrough in concrete technology and an important means to achieve high durability and long life of concrete structures. Because polycarboxylic acid high-performance water-reducing agents have the characteristics of a high rate of water reduction, high performance at a low content, and a small slump loss over time, they have been rapidly developed in regions such as Japan, the United States, and China and are widely used. In recent years, polycarboxylic acid-based high-performance water-reducing agents have been applied in many key projects such as high-speed railways, port and day terminals, hydropower dams, and municipal engineering. They have broad application prospects and will further move toward high-performance and multifunctional. However, many problems have arisen in the application of polycarboxylic acid water reducers, such as insufficient concrete water reduction rate, rapid loss of concrete fluidity, sensitive admixture content and easy segregation of bleeding, slow concrete early strength development, etc. Therefore, the further optimization of the composition and structure of the polycarboxylic acid-based high-performance water-reducing agent is an important research direction to improve its performance and expand its application.

Scholars have conducted a lot of research on the properties of cement-based materials modified by admixtures to improve the mechanical properties and rheological properties of mortar or concrete. Girum et al. [2] investigated the effect of internal curing (IC) by superabsorbent polymers (SAP) on the internal relative humidity (IRH), autogenous shrinkage, coefficient of thermal expansion (CTE), and strength characteristics of low water-cement ratio (w/c) mortars. Kim et al. [3] assessed durability and rheological characteristics of binary blended mixtures incorporating high-volume ground-granulated blast-furnace slag (GGBFS). Yamada et al. [4] studied the dispersion performance of polycarboxylate superplasticizers on cement particles and evaluated the fluidity, plastic viscosity, and shear yield stress of cement slurry under different water-cement ratios $(w / c)$. The relative effectiveness of them as dispersants in cement slurry was also studied. Feys et al. [5] evaluated the effects of mixing time, mixing speed, and superplasticizer addition time on the rheological properties of cement slurry with self-compacting concrete consistency. The results show that changing the water consumption is the main factor affecting the rheology of cement slurry with low water-cement ratio $(w / p)$. Ma et al. [6] studied the effect of polycarboxylate superplasticizers on Fubelite sulfoaluminate cement, and the results showed that the cement setting time depends on the amount of water-reducing agent. Through mercury intrusion method (MIP) and scanning electron microscope (SEM) images and other methods, the compatibility mechanism between polycarboxylate superplasticizer and cement was studied. Uchikawa et al. [7] proved that the polycarboxylate superplasticizer is adsorbed on cement particles and acts through electrostatic and/or steric repulsion. The working performance of cement paste, mortar, and concrete containing polycarboxylic acid superplasticizer depends on various parameters. On the one hand, the type, chemical composition and molecular structure of polycarboxylic acid superplasticizers [8] affect the rheological properties (such as apparent yield stress, viscosity, concrete slump); on the other hand, the chemistry of cement Composition (especially $\mathrm{C}_{3} \mathrm{~A}$ content and soluble sulfate content), specific surface area, the presence of mineral additives or other types of mixtures, all affect the role of superplasticizers in cement paste, mortar, and concrete [9,10].

Good rheological properties help to ensure the working performance of concrete and the stability of the engineering structure, thereby extending the service life of the project. Although traditional working performance testing methods (such as slump and expansion) are simple, their characterization methods are rough, and it is difficult to comprehensively reflect the rheological properties of mortar mixtures. The rheological properties of mortar are the reaction of its structural characteristics. The rheological parameters can conveniently and accurately determine the working performance and fluidity loss of concrete. The structural characteristics of the mortar can be analyzed through the measurement of rheological parameters and the characteristics of rheological curves. This paper 
regards mortar as a complex fluid and establishes the correlation between working performance and rheological parameters, characterizes mortar performance with rheological parameters, and uses bubble characteristic parameters such as pore structure and distribution to accurately characterize the pore morphology and structure of mortar.

In this paper, three functional polycarboxylic acid water reducers are prepared, namely, water reducing polycarboxylic acid water reducing agent $\mathrm{J}$, slow-release polycarboxylic acid water reducing agent $\mathrm{H}$, and early strength polycarboxylic acid water reducing agent $\mathrm{Z}$. These use functional polycarboxylic acid water reducer to control the working performance and mechanical properties of the mortar. Compare the cement mortar without and with different functional polycarboxylic acid superplasticizers, examine the fluidity, time loss and compressive strength of the mortar, analyze different functional polycarboxylic acid superplasticizers and naphthalene. The effect of water reducing agent on the yield stress and plastic viscosity of mortar and the rheology of mortar with functional polycarboxylic acid water reducing agent was studied, and the rheological parameters and bubble characteristic parameters were used to characterize the different effects of water-reducing agents to provide reference and basis for engineering design and construction.

\section{Experimental}

\subsection{Materials}

The raw materials used in this article are shown in Table 1. The molecular structure of the functional polycarboxylic acid water reducing agent is shown in Figures 1-3.

Table 1. List of raw materials.

\begin{tabular}{|c|c|c|}
\hline Raw Materials & Provider & Performance \\
\hline $\begin{array}{l}\text { Water-reducing polycarboxylic } \\
\text { acid superplasticizer J }\end{array}$ & State Key Laboratory of Fine Chemicals & $40 \%$ \\
\hline $\begin{array}{l}\text { Sustained-release } \\
\text { polycarboxylic acid } \\
\text { superplasticizer H }\end{array}$ & State Key Laboratory of Fine Chemicals & $40 \%$ \\
\hline $\begin{array}{l}\text { Early-strength polycarboxylic } \\
\text { acid superplasticizer } Z \text {, }\end{array}$ & State Key Laboratory of Fine Chemicals & $40 \%$ \\
\hline $\begin{array}{l}\text { Early-strength polycarboxylic } \\
\text { acid superplasticizer F }\end{array}$ & Sika (China) Co., Ltd. & $20 \%$ \\
\hline $\begin{array}{l}\text { Naphthalene-basedwater-reducing } \\
\text { agent (NF) }\end{array}$ & Shandong Wanshan Chemical Co., Ltd. & $100 \%$ \\
\hline The ordinary Portland cement & Dalian Onoda Cement Co., Ltd. & Grade $42.5 R$ \\
\hline Standard sand & Xiamen Esi Standard Sand Co., Ltd. & Standard \\
\hline River sand & Dalian Shiyutong Concrete Co., Ltd. & $\begin{array}{l}\text { Fineness modulus of } 2.7, \text { mud } \\
\text { content of } 1.5 \% \text {, firmness of } \\
2 \% \text {, water absorption of } 0.5 \%\end{array}$ \\
\hline Stone & Dalian Limestone Mine & $\begin{array}{l}\text { Apparent density of } 2680 \\
\mathrm{~kg} / \mathrm{m}^{3}, \text { mud content of } 0.3 \% \text {, } \\
\text { and water content of } 0.1 \%\end{array}$ \\
\hline Fly ash & Dalian Huaneng Power Plant & Second level \\
\hline
\end{tabular}

The molecular formulas of the three functional polycarboxylic acid water reducers are as follows: 


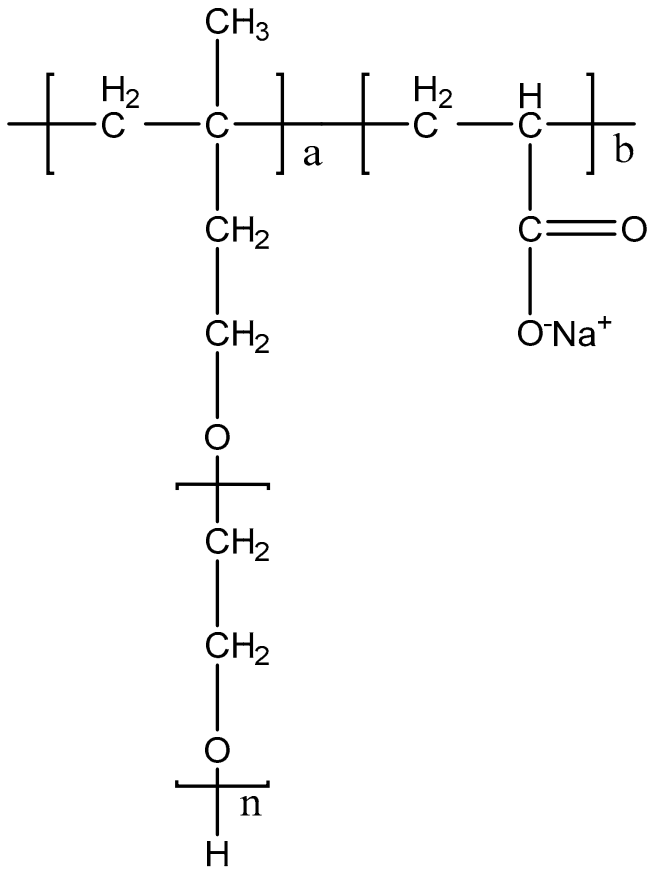

Figure 1. Molecular formula of water-reducing polycarboxylic acid superplasticizer J.

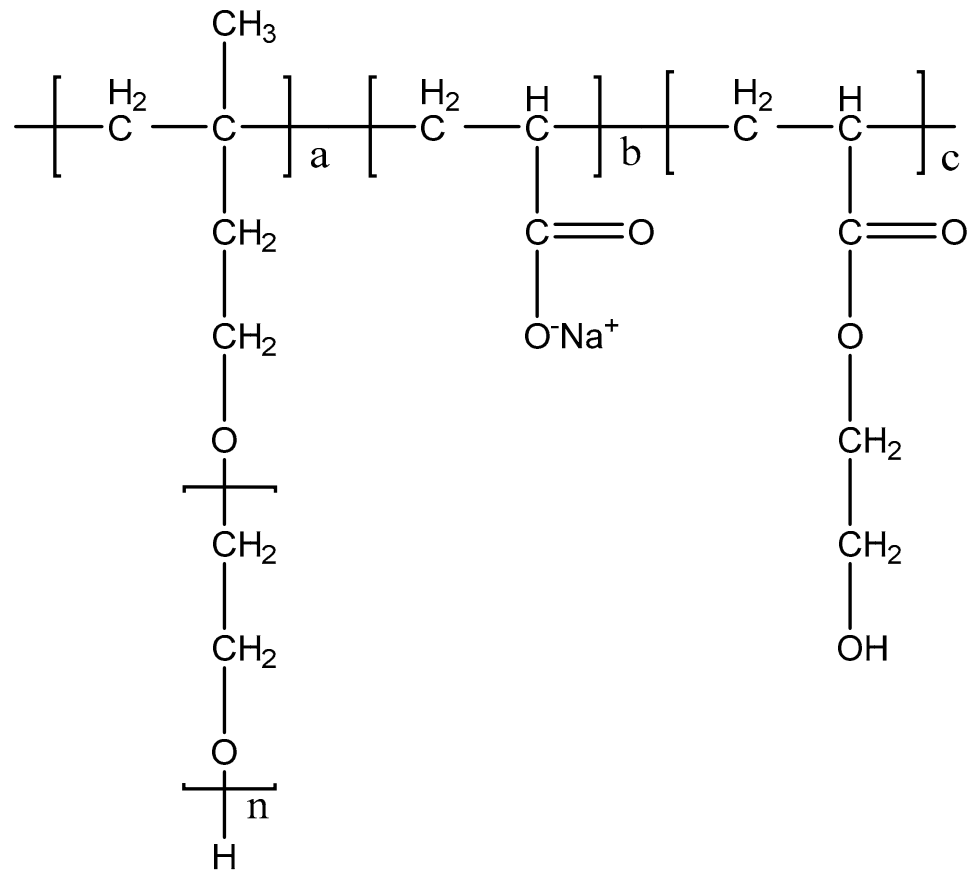

Figure 2. Molecular formula of sustained-release polycarboxylic acid superplasticizer $\mathrm{H}$. 


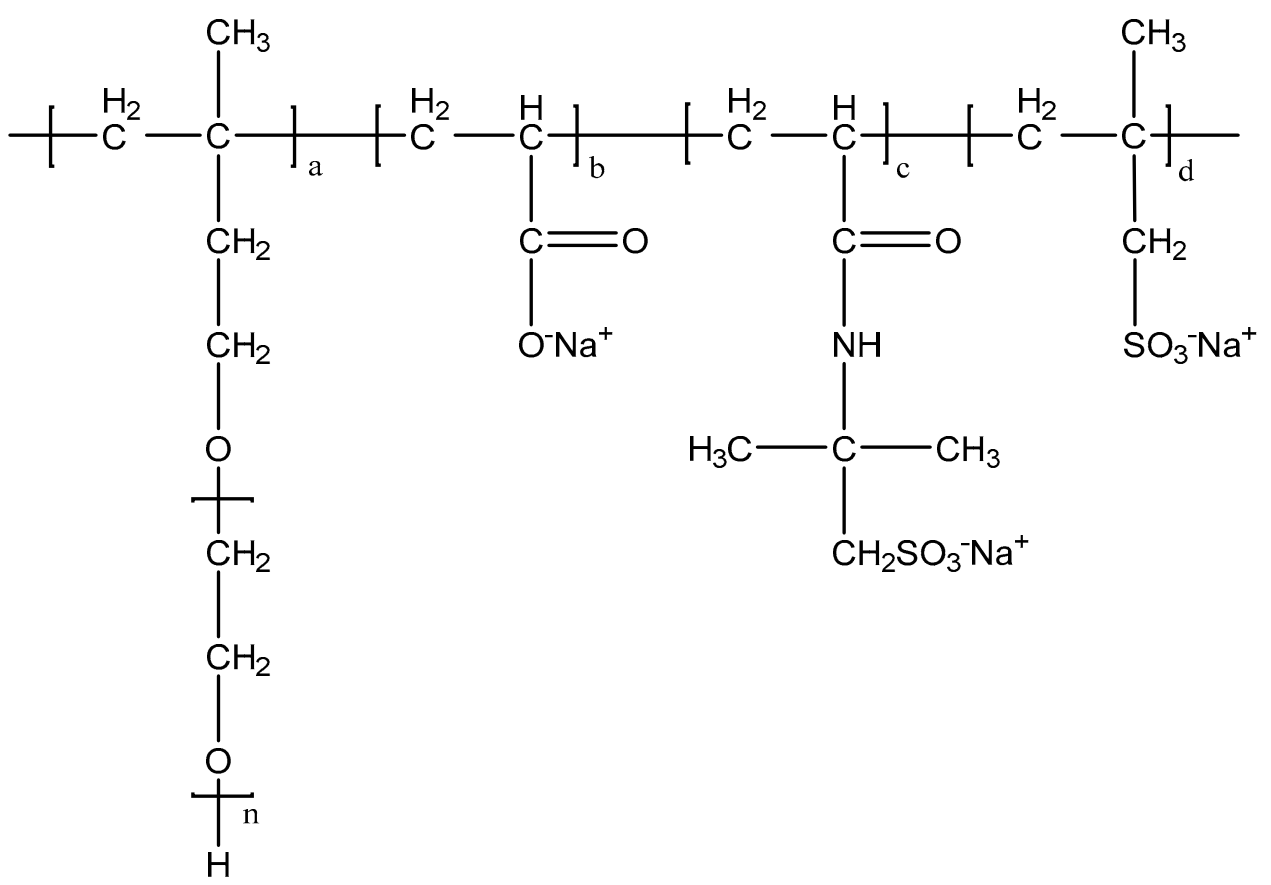

Figure 3. Molecular formula of early-strength polycarboxylic acid superplasticizer Z.

\subsection{Preparation of Samples}

\subsubsection{Cement Paste Ratio}

The composition of the various cement paste samples prepared is summarized in Table 2.

Table 2. The composition of the prepared cement pastes.

\begin{tabular}{ccccc}
\hline Group ID & Cement (g) & $\begin{array}{c}\text { Water-Reducing } \\
\text { Agent Type }\end{array}$ & $\begin{array}{c}\text { Water-Reducing } \\
\text { Agent (g) }\end{array}$ & $\begin{array}{c}\text { Water } \\
\text { Consumption (g) }\end{array}$ \\
\hline B (Blank) & 500 & None & 0 & 115 \\
\hline $\mathrm{H}$ & 500 & $\begin{array}{c}\text { Sustained-release } \\
\text { polycarboxylic acid } \\
\text { superplasticizer H } \\
\text { Z }\end{array}$ & $\begin{array}{c}\text { Early-strength } \\
\text { polycarboxylic acid } \\
\text { superplasticizer Z }\end{array}$ & 3.0 \\
\hline $\mathrm{NF}$ & 500 & $\begin{array}{c}\text { Naphthalene-based } \\
\text { water-reducing agent } \\
\text { Water-reducing } \\
\text { polycarboxylic acid } \\
\text { superplasticizer J }\end{array}$ & 3.9 & 115 \\
\hline $\mathrm{J}$ & 500 & 3.0 & 115 \\
\hline
\end{tabular}

\subsubsection{Mortar Mix Ratio}

To examine the effect of different admixtures on the rheological properties of the cement mortar, except for the naphthalene-based water-reducing agent, the water-to-cement and the sand-to-cement mass ratios were set at 0.33 and 2.0 respectively. The solid content of the polycarboxylic acid superplasticizer of $40 \%$ accounts for $0.24 \%$ of the cement mass, and the naphthalene (powder) content accounts for $1.3 \%$ of the cement mass. The mix ratio of the cement mortar is listed in Table 3. 
Table 3. Mix ratio of the cement mortar.

\begin{tabular}{cccccc}
\hline Sample ID & $\begin{array}{c}\text { Cement } \\
\text { (g) }\end{array}$ & $\begin{array}{c}\text { Sand } \\
\text { (g) }\end{array}$ & $\begin{array}{c}\text { Water-Reducing } \\
\text { Agent (g) }\end{array}$ & $\begin{array}{c}\text { Water } \\
\text { Consumption (g) }\end{array}$ & $\begin{array}{c}\text { Water-Reducing Agent } \\
\text { Type }\end{array}$ \\
\hline B1 & 1181 & 2363 & 0 & 400.0 & No water-reducing agent \\
\hline B2 & 1181 & 2363 & 0 & 600.0 & No water-reducing agent \\
\hline J1 & 1181 & 2363 & 7.08 & 392.6 & $\begin{array}{c}\text { Water-reducing } \\
\text { polycarboxylic acid } \\
\text { superplasticizer J }\end{array}$ \\
\hline H1 & 1181 & 2363 & 7.08 & 392.6 & $\begin{array}{c}\text { Sustained-release } \\
\text { polycarboxylic acid } \\
\text { superplasticizer H }\end{array}$ \\
\hline Z1 & 1181 & 2363 & 15.36 & 392.6 & $\begin{array}{c}\text { Naphthalene-based } \\
\text { water-reducing agent NF }\end{array}$ \\
\hline Z2 & 1181 & 2363 & 7.08 & 392.6 & $\begin{array}{c}\text { Early-strength } \\
\text { polycarboxylic acid } \\
\text { superplasticizer Z }\end{array}$ \\
\hline & 1181 & 2363 & 5.90 & 392.6 & $\begin{array}{c}\text { Early-strength } \\
\text { polycarboxylic acid } \\
\text { superplasticizer Z }\end{array}$ \\
\hline
\end{tabular}

\subsubsection{Analysis of Mortar Rheology}

The rheology of the freshly mixed cement mortar has been studied by a number of scholars [11-17], and it can be approximated by the Bingham plastic rheological model. This model uses two material constants, namely the shear yield stress and plastic viscosity, to determine the rheological properties of the concrete mixture as expressed in Equation (1):

$$
\tau=\tau_{0}+\eta \gamma,
$$

where $\tau$ is the shear stress to which the material is subjected; $\tau_{0}$ and $\eta$ represent the shear yield stress and plastic viscosity of the material respectively; $\gamma$ stands for the shear rate to which the material is subjected.

The shear yield stress caused by the adhesion and friction between the particles in the mortar slurry is the maximum stress that prevents the plastic deformation of the slurry and determines the deformation properties of the mixture. The performance of the body structure hindering the flow reflects the rate of deformation of the cement mortar and thus the fluidity of the mixture. Yield stress and plastic viscosity are related to factors such as particle shape and the thickness distribution of the cement mortar. The smaller the shear yield stress is, the better the fluid flows.

This paper mainly studies the effect of functional polycarboxylic acid superplasticizers on the rheological properties of fresh cement mortar and uses a naphthalene-based superplasticizer for comparison. Viskomat XL rheometer (Schleibinger, Germany) is also utilized to examine the rheological parameters of the fresh cement mortar mixed with different functional admixtures.

The rheometer speed is set to start from $0 \mathrm{rpm}$ and increase in steps of $10 \mathrm{rpm}$; each step lasts for $30 \mathrm{~s}$, and one set of performance data on the rheological properties of mortar is measured during each step; the rheometer stops recording data at a maximum speed of $100 \mathrm{rpm}$ after $5 \mathrm{~min}$. The linear regression of the rheological parameters of the cement mortar at each speed was used to obtain the rheological parameters of each group of cement mortar, and the data obtained from the experiments of each group in Table 3 were then processed and plotted.

Sample 1 in Table 2 has a large loss of fluidity over time, and after a period of standing time, it cannot be tested with a rheometer. However, the rheological properties of cement mortar samples $2-7$ are analyzed. 


\subsection{Characterization}

\subsubsection{Compressive Strength Analysis}

Small cubic samples $(20 \mathrm{~mm} \times 20 \mathrm{~mm} \times 20 \mathrm{~mm}$ ) were prepared to minimize the cement pastes used in the analysis of compressive strength. The clinker samples with or without gypsum addition were incorporated using deionized water and a water-to-cement ratio of 0.4 . In the molding process, only simple ramming is performed, and the mold does not use the vibration table because this water-to-cement ratio is a typical ratio used in general projects and is sufficient to form workable pastes. When the pastes were poured into molds, every mold surface was covered with plastic film, and they were then placed in a standard curing box. After testing the compressive strength of the samples, the center of the block was extracted as the sample pastes for characterization.

\subsubsection{TG-DTG Analysis}

The TG-DTG analysis was performed using a Mettler Toledo TG/DSC instrument. The powdered cured samples $(10 \pm 1 \mathrm{mg})$ were placed in $70 \mathrm{~L}$ corundum crucibles covered with corundum lids, and the analysis was conducted $10{ }^{\circ} \mathrm{C} / \mathrm{min}$; nitrogen was used as a protective gas. Finally, the TG data were processed using the Free STARe Evaluation Software.

\subsubsection{Mercury Intrusion Porosimetry Analysis}

Mercury intrusion porosimetry (MIP) was conducted using an AUTOPORE IV 9500 (a maximum pressure of 33,000 psia) series made by Micromeritics Instrument Corp., the USA, to characterize the pore size distribution of the samples. To this end, some pieces of block samples of about 1.5-2.5 g were used for the analysis, and the samples were dried in a vacuum drying oven at $35^{\circ} \mathrm{C}$ for $24 \mathrm{~h}$ to remove the water from the porous structure of the samples.

\section{Results and Discussion}

\subsection{Cement Paste Analysis}

\subsubsection{Cement Slurry Fluidity}

According to Table 4, summarizing the flow performance of the cement paste in the presence of various functional polycarboxylic acid superplasticizers, group B, as a blank (control) group, contains no water-reducing agent, while the other groups are mixed with different water-reducing agents. Under the same water consumption (water-to-cement ratio), the fluidity of groups B and $\mathrm{H}$ is poor in the initial state. Groups $\mathrm{Z}$ and $\mathrm{H}$ offer the best fluidity $(280 \mathrm{~mm})$, and group ZF has intermediate fluidity $(160 \mathrm{~mm})$. After 1 and $2 \mathrm{~h}$, groups $\mathrm{B}$ and NF do not flow, but the fluidity of the cement paste in group $\mathrm{H}$ was 230 and $255 \mathrm{~mm}$ respectively after 1 and $2 \mathrm{~h}$, indicating that the cement paste of group $\mathrm{H}$ has a sustained-release effect mainly due to the slow-release property of the water-reducing agent $\mathrm{H}$. In fact, hydroxyethyl groups available in the water-reducing agent $\mathrm{H}$ undergo hydrolysis reaction in the presence of alkaline substances (mainly calcium hydroxide) in cement and gradually release carboxyl water-reducing groups, therefore the fluidity of the cement paste gradually increases. The fluidity of the cement paste of groups $Z$ and $J$ gradually decreases, implying that superplasticizers $\mathrm{Z}$ and $\mathrm{J}$ do not have a sustained-release effect on the cement. 
Table 4. Effects of functional polycarboxylic acid superplasticizers on the flow performance of the cement paste.

\begin{tabular}{|c|c|c|c|c|c|}
\hline \multirow[b]{2}{*}{ Group ID } & \multirow[b]{2}{*}{$\begin{array}{c}\text { Water-Reducing } \\
\text { Agent (g) }\end{array}$} & \multirow{2}{*}{$\begin{array}{c}\text { Water } \\
\text { Consumption } \\
(\mathrm{g})\end{array}$} & \multicolumn{3}{|c|}{ Cement Slurry Flow } \\
\hline & & & $\begin{array}{l}\text { Initial Cement } \\
\text { Slurry Flow } \\
(\mathrm{mm})\end{array}$ & $\begin{array}{c}\text { Fluidity of } \\
\text { Cement Paste } \\
\text { after } 1 \mathrm{~h}(\mathrm{~mm})\end{array}$ & $\begin{array}{c}\text { Fluidity of } \\
\text { Cement Paste } \\
\text { after } 2 \mathrm{~h}(\mathrm{~mm})\end{array}$ \\
\hline B (Blank) & 0.0 & 115 & No flow, dry & No flow, dry & No flow, dry \\
\hline $\mathrm{H}$ & 3.0 & 115 & No flow & 230 & 255 \\
\hline $\mathrm{Z}$ & 3.0 & 115 & 280 & 255 & 240 \\
\hline NF & 3.9 & 115 & 160 & No flow & No flow \\
\hline $\mathrm{J}$ & 3.0 & 115 & 280 & 280 & 270 \\
\hline
\end{tabular}

\subsubsection{Mechanical Properties of Cement Paste}

Table 5 lists the compressive strength of the cement paste mixed with different superplasticizers. Group B, the blank group, has the lowest compressive strength after 1, 7, and 28 days, followed by groups $\mathrm{H}$ and NF. Groups $\mathrm{Z}$ and $\mathrm{J}$ have the highest compressive strength. Group $\mathrm{Z}$ reaches the maximum compressive strength after 1 day, indicating that the early-strength superplasticizer $Z$ used in this group has the effect of providing early strength because it contains amine and sulfonic groups which can promote cement hydration by increasing the rate of hydration reactions. Group J has the highest compressive strength after 28 days, which is $30 \%$ higher than the blank group without water reducing agent, implying that the water-reducing agent used in this group can have a good water-reducing effect and can improve the pore structure of the cement paste, thereby enhancing the compactness of the cement paste.

Table 5. Effects of functional polycarboxylic acid superplasticizers on the compressive strength of the cement paste.

\begin{tabular}{cccccc}
\hline \multirow{2}{*}{ Group ID } & \multirow{2}{*}{$\begin{array}{c}\text { Water-Reducing } \\
\text { Agent (g) }\end{array}$} & $\begin{array}{c}\text { Water } \\
\text { Consumption (g) }\end{array}$ & \multicolumn{3}{c}{$\begin{array}{c}\text { Compressive Strength } \\
\text { (MPa) }\end{array}$} \\
\cline { 4 - 6 } & & & 1 Day & 7 Days & 28 Days \\
\hline B (Blank) & 0 & 115 & 51.5 & 63.0 & 75.5 \\
H & 3.0 & 115 & 67.1 & 75.6 & 87.5 \\
Z & 3.0 & 115 & 76.8 & 89.0 & 95.8 \\
NF & 3.9 & 115 & 69.6 & 73.4 & 90.6 \\
J & 3.0 & 115 & 74.6 & 86.1 & 97.9 \\
\hline
\end{tabular}

\subsubsection{Heat of Cement Hydration}

As can be seen in Figure 4, compared with the blank group, the addition of water-reducing agents NF, H, Z, and J to the cement has a retarding effect, which extends the induction period of cement hydration. In particular, the longer induction period of cement hydration in the presence of water-reducing agents $\mathrm{H}, \mathrm{Z}$, and J demonstrates that polycarboxylic acid superplasticizers, due to the long side chains and a strong steric hindrance effect, have a more significant retarding impact than the naphthalene-based water-reducing agent. The molecular structure of polycarboxylic acid superplasticizers contains functional groups, such as ether and carboxyl groups, adsorbed on the surface of cement particles, which prevent water molecules from approaching cement due to shielding and hinder the cement hydration reactions. Therefore, polycarboxylic acid water-reducing agents have a substantial retarding effect on cement hydration. On the other hand, the naphthalene-based water-reducing agent (NF) only contains sulfonic acid groups with shorter chains and a weaker steric hindrance effect, hence it cannot retard cement hydration as good as polycarboxylic acid water-reducing agents. 


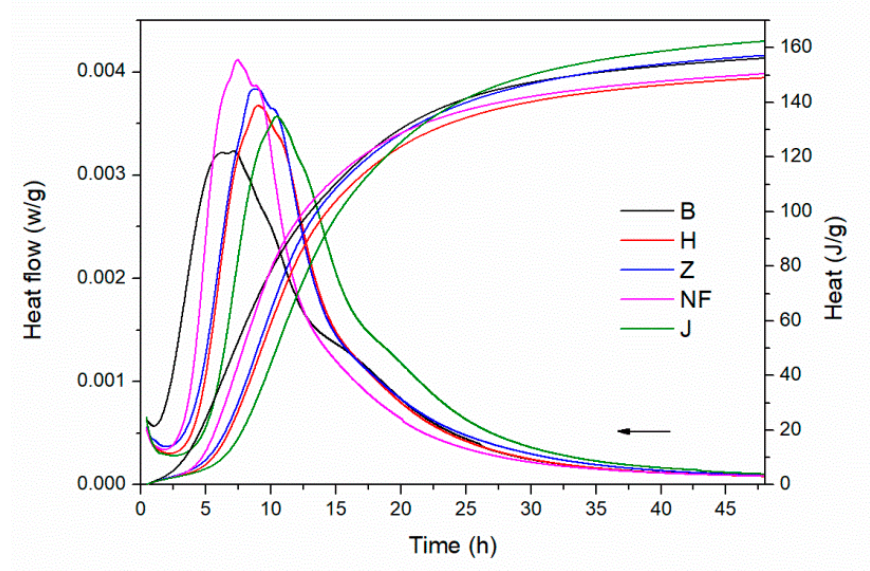

Figure 4. Effects of different superplasticizers on the heat of cement hydration.

\subsubsection{Glass Transition Temperature}

Figures 5-7 illustrate the effects of different superplasticizers on cement hydration at different ages $(1,7$, and 28 days). It is obvious that at an age of 1 day, group $H$ generates the least amount of alumina, ferric oxide, tri-sulfate (AFt) (the smallest peak), while group NF produces the highest amount of AFt (the largest peak), indicating that the water-reducing agent of group $\mathrm{H}$ has a retarding effect on the cement hydration. In fact, superplasticizer $\mathrm{H}$ is adsorbed on the surface of the cement minerals and forms a film, which retards the cement hydration reactions, thereby resulting in the least amount of produced AFt and leading to the greatest impact on cement hydration. Nonetheless, the naphthalene-based water-reducing agent contains a large amount of sodium sulfate, which can promote the formation of $\mathrm{AFt}$, hence group NF generates the highest amount of alumina, ferric oxide, tri-sulfate. At the ages of 7 and 28 days, the amount of AFt formed by the various groups was basically the same, implying that the water-reducing agent has a small impact on the late cement hydration.

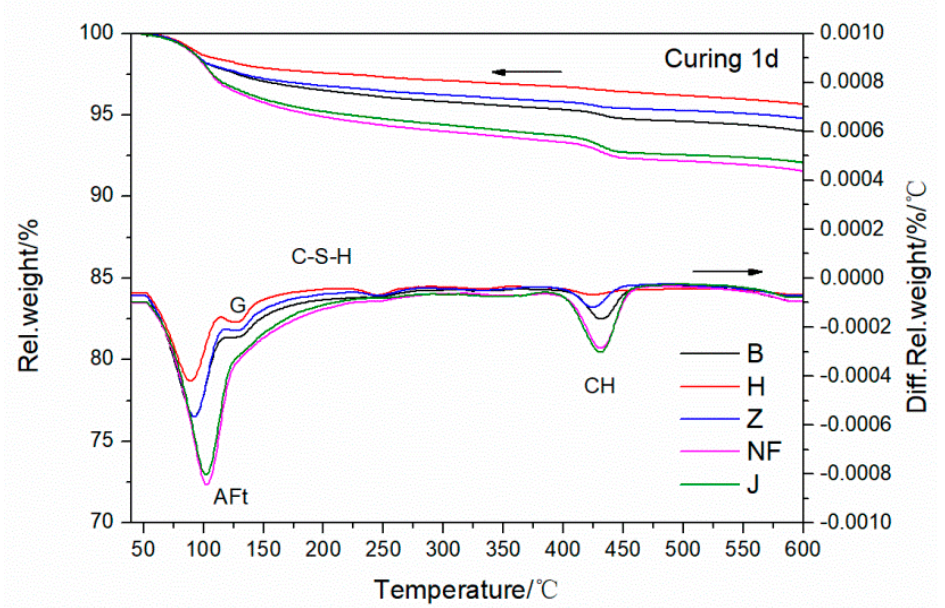

Figure 5. Effects of different superplasticizers on cement hydration after 1 day. 


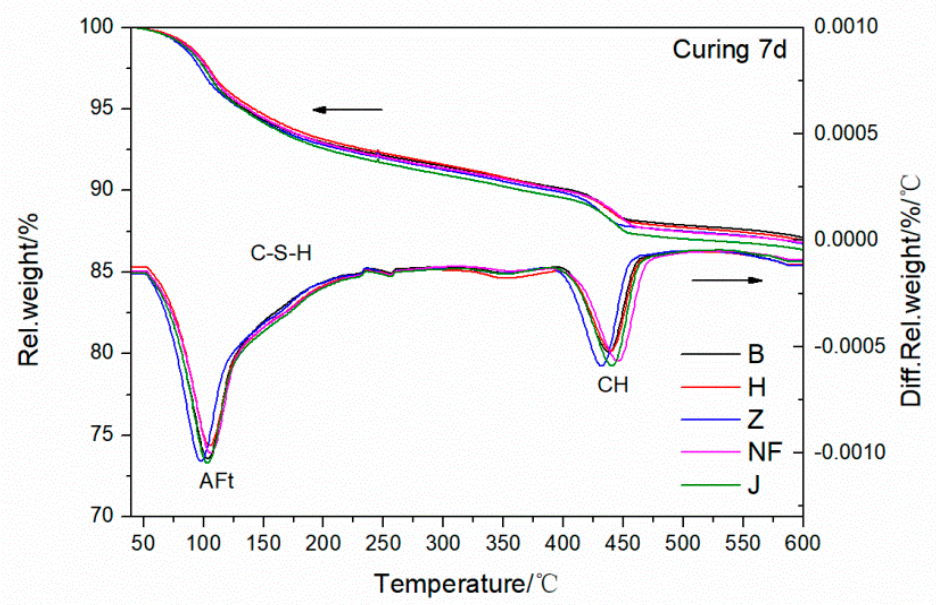

Figure 6. Effects of different superplasticizers on cement hydration after 7 days.

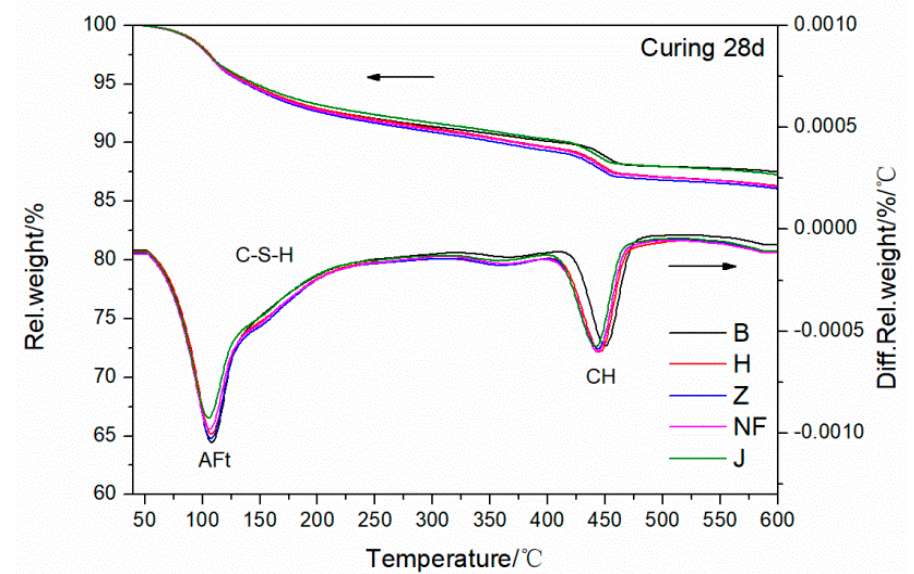

Figure 7. Effects of different superplasticizers on cement hydration after 28 days.

\subsubsection{Mercury Intrusion Porosimetry}

The pore structure, i.e., the average pore size, pore size distribution, and total porosity, is the main factor affecting the strength and durability of cement-based materials. Figure 8 depicts the effect of different superplasticizers on the pore structure of the cement paste. Compared with the blank group, although the addition of various water-reducing agents causes the median pore size to shift slightly toward large pore sizes, the cumulative amount of mercury intrusion decreases, demonstrating that the overall porosity is reduced. In fact, since superplasticizer J has the effect of reducing water, it promotes the hydration of cement, improves the compactness of the mortar, and reduces the total number of pores in the hardened mortar. Furthermore, the comparison of macroscopic mechanical properties of the groups containing various superplasticizers reveals that after 28 days the compressive strength of the cement paste of groups $\mathrm{B}, \mathrm{H}, \mathrm{NF}, \mathrm{Z}$, and J is 75.5, 87.5, 90.6, 95.8, and 97.9 MPa respectively, which confirms that superplasticizer $\mathrm{J}$ is the most influential superplasticizer in terms of reducing water, promoting cement hydration, and enhancing the compactness of cement mortar. 


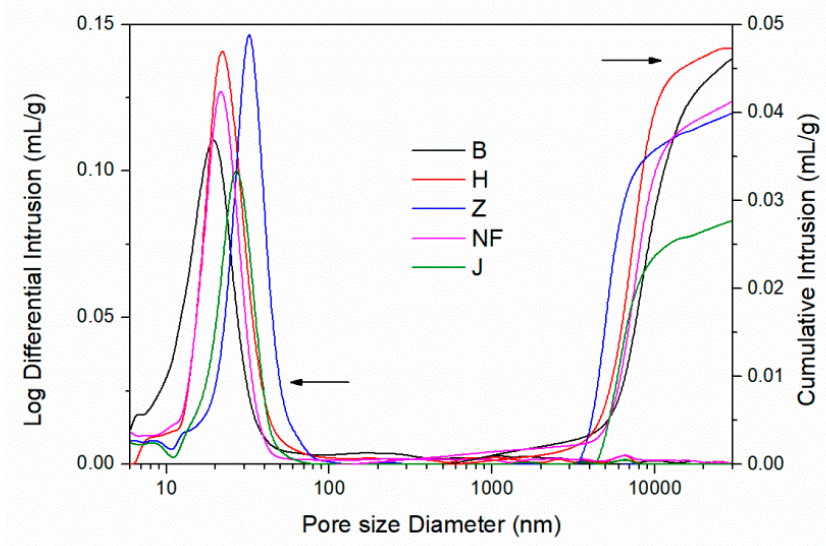

Figure 8. Effects of different superplasticizers on the cumulative pore volume of the cement paste.

\subsection{Mortar Analysis}

\subsubsection{Mortar Fluidity}

Generally, to evaluate the workability of fresh mortar, its rheological properties are analyzed under different conditions. A common method to test the rheological properties is to measure the fluidity of freshly mixed mortar. To this end, the initial fluidity of the mortar and the fluidity of the mortar after $1 \mathrm{~h}$ plus $40 \mathrm{~min}$ are measured, as depicted in Figure 9.

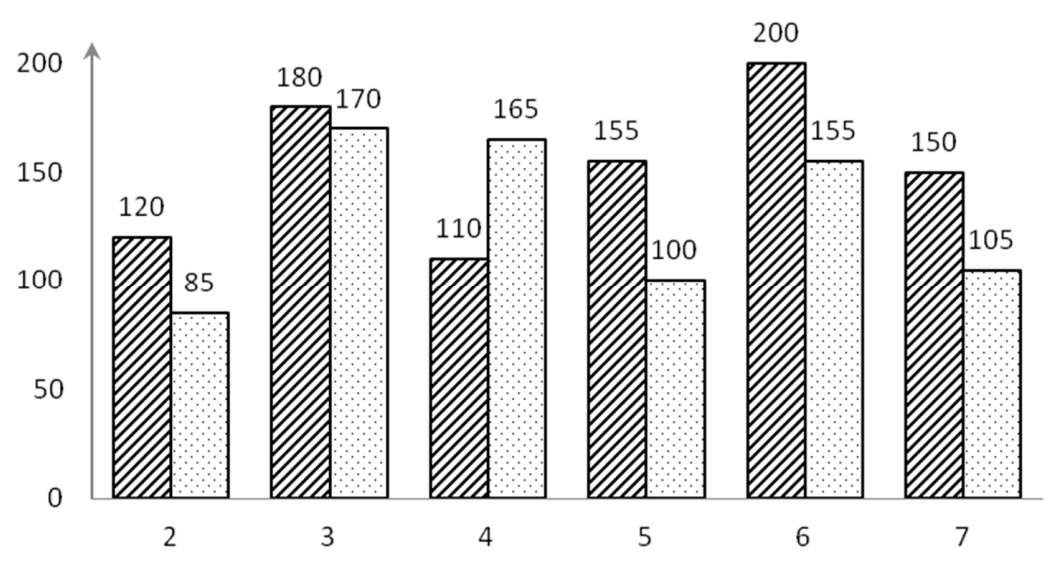

Figure 9. Fluidity of the mortar: diagonal stripes denote initial mortar fluidity and dots denote mortar fluidity after $1 \mathrm{~h}$ plus $40 \mathrm{~min}$.

As tabulated in Table 6, under the same water consumption conditions, sample 1 of the blank group shows no initial fluidity and slightly bleeds after $1 \mathrm{~h}$ plus $40 \mathrm{~min}$. Sample 2 of the blank group (light bleeding) is prepared by increasing the water consumption from 400 to $600 \mathrm{~g}$; it is clear that increasing water consumption leads to poor workability, therefore increasing the water-to-cement ratio is not recommended. Samples 1 and 2 were selected as the control group.

The comparison between samples 2 and 3 reveals that the initial fluidity of sample $3(180 \mathrm{~mm})$ is much larger than that of sample 2 (120 mm, light bleeding). The fluidity of sample 3 after $1 \mathrm{~h}$ plus $40 \mathrm{~min}(170 \mathrm{~mm})$ still remains good, and its fluidity loss over time is small (5.9\%), which confirms that water-reducing polycarboxylic acid superplasticizer J has better water-reducing and slump retention properties.

Sample 4 contains a sustained-release polycarboxylic acid high-performance water-reducing agent. The initial fluidity of sample $4(110 \mathrm{~mm})$ is slightly less than that of sample $2(120 \mathrm{~mm})$, and its fluidity increases with time (165 mm after $1 \mathrm{~h}$ plus $40 \mathrm{~min}$ ), indicating that the water-reducing effect of the superplasticizer $\mathrm{H}$ is gradually produced after $1 \mathrm{~h}$ plus $40 \mathrm{~min}$, that the fluidity still improves, and that there is no loss of fluidity over time. 
Table 6. The fluidity and compressive strength of cement mortar.

\begin{tabular}{|c|c|c|c|c|c|c|c|}
\hline Sample ID & $\begin{array}{c}\text { Water-Reducing } \\
\text { Agent Type }\end{array}$ & $\begin{array}{l}\text { Initial Mortar } \\
\text { Fluidity (mm) }\end{array}$ & $\begin{array}{l}\text { Mortar Fluidity } \\
\text { after } 1 \mathrm{~h} \text { Plus } 40 \\
\min (\mathrm{mm})\end{array}$ & $\begin{array}{c}\text { Loss of } \\
\text { Fluidity over } \\
\text { Time (mm) }\end{array}$ & $\begin{array}{c}\text { Loss of } \\
\text { Fluidity over } \\
\text { Time }(\%)\end{array}$ & $\begin{array}{c}\text { Mortar } \\
\text { Compressive } \\
\text { Strength after } 1 \\
\text { Day (MPa) }\end{array}$ & $\begin{array}{c}\text { Mortar } \\
\text { Compressive } \\
\text { Strength after } 7 \\
\text { Days (MPa) }\end{array}$ \\
\hline 1 & None & No fluidity & Bleeding & - & - & - & - \\
\hline 2 & None & 120 & 85 & 35 & 41.2 & 20.8 & 33.0 \\
\hline 3 & $\mathrm{~J}$ & 180 & 170 & 10 & 5.9 & 36.1 & 53.0 \\
\hline 4 & $\mathrm{H}$ & 110 & 165 & -55 & -33.3 & 26.2 & 39.4 \\
\hline 5 & $\mathrm{NF}$ & 155 & 100 & 55 & 55.0 & 38.3 & 61.2 \\
\hline 6 & $\mathrm{Z}$ & 200 & 155 & 45 & 29.0 & 46.4 & 67.3 \\
\hline 7 & Z & 150 & 105 & 45 & 42.9 & 46.3 & 66.5 \\
\hline
\end{tabular}


Although the initial fluidity of sample $5(155 \mathrm{~mm})$ is higher than that of the blank sample 2, its initial fluidity is less compared to sample $3(180 \mathrm{~mm})$, and its rate of fluidity loss over time $(55 \mathrm{~mm})$ is much greater than that of sample $3(10 \mathrm{~mm})$, which reflects the influence of polycarboxylic acid high-performance water-reducing agent. Thus, superplasticizer $\mathrm{J}$ is better than naphthalene-based water-reducing agent and has better adaptability to cement.

The initial fluidity of samples 6 and 7 (which are based on superplasticizer Z) is much higher than that of the blank sample, i.e., sample 2, indicating that increasing the amount of early-strength polycarboxylic acid high-performance water-reducing agent improves the fluidity of cement mortar; however, it seems that the change of the dosage of superplasticizer has no obvious impact on the compressive strength of the cement mortar after 1 day (compare sample 6 with sample 7). Moreover, the compressive strength of the cement mortar mixed with early-strength polycarboxylic acid high-performance water-reducing agent is higher than that of the other mortars after 1 and 7 days, which proves the influence of superplasticizer $Z$ on improving the early strength of the mortar.

According to Table 6 , the early strength (after 1 and 7 days) of mortar sample 6 is higher than that of mortar sample 3, denoting that the early-strength polycarboxylic acid high-performance superplasticizer $\mathrm{Z}$ is superior to the water-reducing polycarboxylic acid high-performance superplasticizer J. The main reason that early-strength polycarboxylic acid superplasticizer improves the early strength of mortar is that it contains ultra-long side-chain polyoxyethylene functional groups which retard the cement hydration more than the water-reducing polycarboxylic acid superplasticizers J. The side chains of the early-strength polycarboxylic acid high-performance water-reducing agent $Z$ contain an amine-based functional group, which can accelerate the cement hydration process and thus improves the early strength of cement mortar compared with water-reducing polycarboxylic acid superplasticizer J.

\subsubsection{Mortar Rheological Analysis}

According to the initial rheological properties of the mortar samples delineated in Figure 10, there is a linear relationship between shear stress and shear rate (rheometer speed). The initial shear yield stress $\tau_{0}$ value of the mortar samples follows the order sample $6<$ sample $4<$ sample $3<$ sample $2<$ sample $7<$ sample 5 , and the order of the plastic viscosity $\eta$ value of the mortar samples is sample $2<$ sample $3<$ sample $4<$ sample $5<$ sample $6<$ sample 7 . Under the same rotational speed, the corresponding shear stress $\tau$ sequence in the initial state of the mortar is: $2 \#<3 \#<4 \#<6 \#<5 \#<7 \#$, and the shear stress of the mortar gradually increases in this sequence.

The collected data on the rheological properties (shear stress-shear rate variation) of the mortar samples after $1 \mathrm{~h}$ plus $40 \mathrm{~min}$ are presented Figure 11:

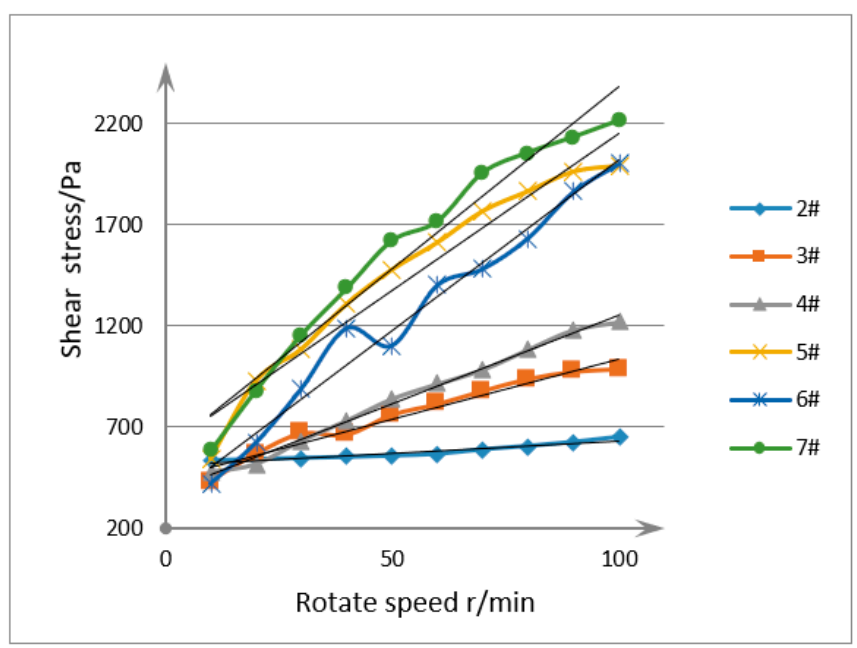

Figure 10. The initial flow properties (shear stress-shear rate variation) of the samples. 


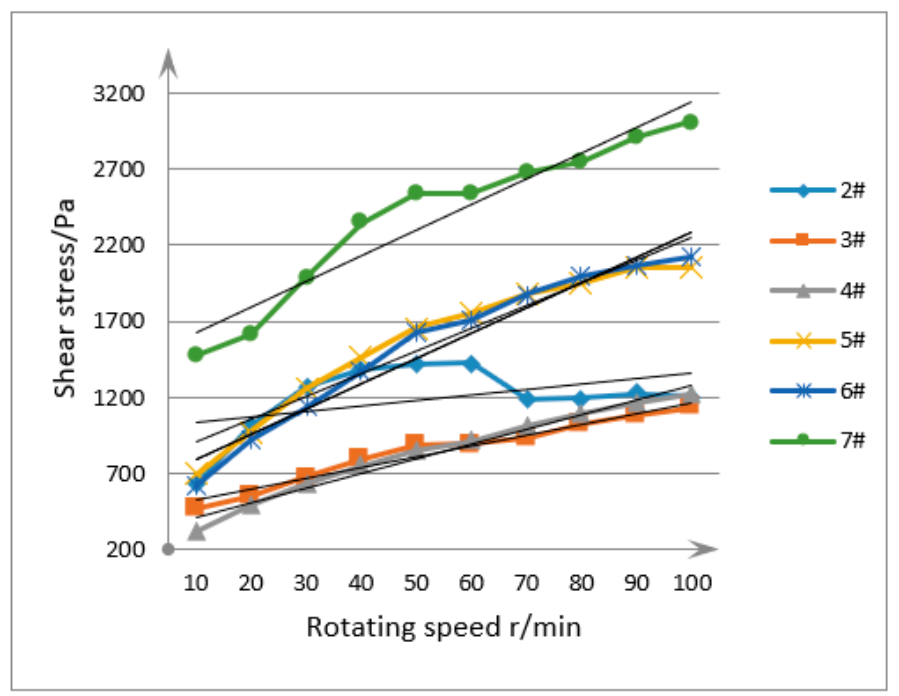

Figure 11. The flow properties (shear stress-shear rate variation) of the samples after $1 \mathrm{~h}$ plus $40 \mathrm{~min}$.

The shear yield stress $\tau_{0}$ value of the mortar samples after $1 \mathrm{~h}$ plus $40 \mathrm{~min}$ follows the order sample $4<$ sample $3<$ sample $6<$ sample $5<$ sample $2<$ sample 7 , and the order of the plastic viscosity $\eta$ value of the mortar samples is sample $2<$ sample $3<$ sample $4<$ sample $5<$ sample $6<$ sample 7 . Comparing Figures 8 and 9 reveals that the shear stress of sample 2, lacking any superplasticizer, poorly follows a linear correlation with shear rate, indicating that the cement mortar tends to flocculate. As the rheometer speed increases, the shear stress $\tau$ rises sufficiently to suppress the interlocking of the cement particles and therefore destroy the agglomerated structure formed by flocculation; thus, the cement mortar obtains a certain degree of fluidity again. It is also clear that the amplitude of the variation in the shear yield stress $\tau$ of samples 3 and 4 is smaller, and the plastic viscosity of the samples represented by the slope of the curves is also lower. The larger y-intercepts of the curves of samples 6 and 7 indicate that the shear yield stress $\tau$ of the mortar samples is larger, and a larger slope of these curves also represents higher plastic viscosity $\eta$. Additionally, the effect of early-strength functional polycarboxylic acid water-reducing agent, as a high-performance superplasticizer accelerating the cement hydration reactions, on the shear behavior of the cement mortar is more obviously reflected.

The initial flow, shear yield stress $\left(\tau_{0}\right)$, and plastic viscosity $(\eta)$ of the mortar samples are also tabulated in Table 7.

Table 7. The fluidity and compressive strength of cement mortar.

\begin{tabular}{ccccccc}
\hline $\begin{array}{c}\text { Sample } \\
\text { ID }\end{array}$ & $\begin{array}{c}\text { Water-Reducing } \\
\text { Agent Type }\end{array}$ & $\begin{array}{c}\text { Initial Flow } \\
\mathbf{( m m )}\end{array}$ & $\begin{array}{c}\text { Initial } \\
\boldsymbol{\tau}_{\mathbf{0}} \mathbf{( P a )}\end{array}$ & $\begin{array}{c}\text { Initial } \boldsymbol{\eta} \\
\mathbf{( P a} \cdot \mathbf{s})\end{array}$ & $\begin{array}{c}\boldsymbol{\tau}_{\mathbf{0}} \mathbf{( P a )} \text { after } \mathbf{1} \\
\mathbf{h} \text { Plus 40 } \mathbf{m i n}\end{array}$ & $\begin{array}{c}\eta \mathbf{P a} \cdot \mathbf{s}) \text { after 1 } \\
\mathbf{h} \text { Plus 40 } \mathbf{m i n}\end{array}$ \\
\hline 2 & None & 120 & 508.39 & 1.23 & 1000.00 & 3.54 \\
3 & $\mathrm{~J}$ & 180 & 436.24 & 6.03 & 450.79 & 7.15 \\
4 & $\mathrm{H}$ & 110 & 378.20 & 8.72 & 309.78 & 9.71 \\
5 & $\mathrm{NF}$ & 155 & 596.03 & 15.57 & 755.57 & 14.88 \\
6 & $\mathrm{Z}$ & 200 & 334.24 & 16.85 & 630.98 & 16.58 \\
7 & $\mathrm{Z}$ & 150 & 576.94 & 18.04 & 1460.90 & 16.79 \\
\hline
\end{tabular}

According to Table 7, the plastic viscosity $\eta$ of the mortar samples mixed with the functional polycarboxylic acid superplasticizer is higher than that of the blank sample, while their fluidity, except for sample 4 containing superplasticizer $\mathrm{H}$, is greater compared to the blank sample. Except for the naphthalene-based superplasticizer and early-strength functional polycarboxylic acid superplasticizer $Z$, the other mortar samples have smaller shear yield stress $\tau$ and better fluidity compared to the blank group. Further, functional polycarboxylic acid superplasticizers can effectively improve the rheological properties of fresh mortar. Specifically, compared to sample 5, which contains 
naphthalene-based water-reducing agent, sample 3 containing superplasticizer J has lower plastic viscosity and higher fluidity, which indicates that the performance of water-reducing functional polycarboxylic acid high-performance superplasticizer $\mathrm{J}$ is superior to that of naphthalene-based water-reducing agent.

Moreover, unlike the other groups, the shear stress of the cement mortar mixed with sustained-release polycarboxylic acid superplasticizer $H$, i.e., sample 4 , gradually decreases within $1 \mathrm{~h}$ plus $40 \mathrm{~min}$, but its plastic viscosity slightly increases. Good slump retention implies that the sustained-release polycarboxylic acid admixture not only delays the hydration of cement but also better disperses the cement particles in the mortar, therefore it can retain the good fluidity of the mortar at the same time. Moreover, sustained-release functional polycarboxylic acid superplasticizer $\mathrm{H}$, thanks to its polyoxyethylene and hydroxyethyl functional groups, gradually produces the effect of reducing water. As the cement hydration progresses, the hydroxyl group of ethyl ester reacts with the alkali generated by the hydration of the cement to form a carboxyl water-reducing group, thereby continuously facilitating the dispersion of the cement particles in the mortar and producing a plasticizing effect.

It can be inferred from Figure 12 that the addition of early-strength polycarboxylic acid superplasticizer can increase the plastic viscosity of the cement mortar. Furthermore, the influence of the amount of early-strength polycarboxylic acid high-performance superplasticizer on the cement mortar is examined. The plastic viscosity of sample 7, containing $5.90 \mathrm{~g}$ of superplasticizer $\mathrm{Z}$, is lower than that of sample 6 with $7.08 \mathrm{~g}$ of superplasticizer Z. Increasing the amount of superplasticizer reduces the plastic viscosity and shear yield stress of the cement mortar, which indicates that a higher amount of the water-reducing agent (7.08 $\mathrm{g}$ of superplasticizer $\mathrm{Z}$ in sample 6) is more effective. In addition, in terms of the mortar flow properties, the sample containing a higher amount of the early-strength polycarboxylic acid superplasticizer, i.e., sample 6, has higher fluidity. In fact, the smaller the shear yield stress is, the better the fluidity becomes; the plastic viscosity also reflects the internal friction between the cement particles in the mortar. Therefore, the early-strength polycarboxylic acid superplasticizer can effectively reduce the yield stress and plastic viscosity of the mortar and is able to improve the fluidity (compare blank sample 2 with sample 6).

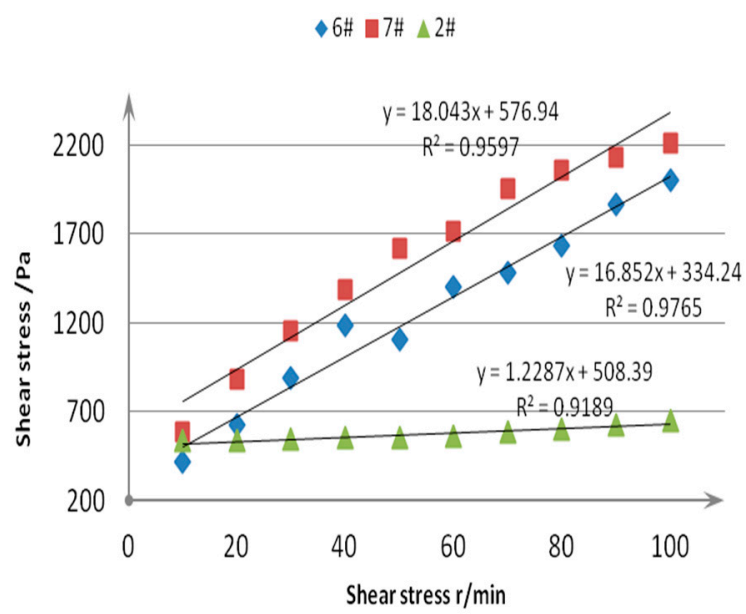

Figure 12. The flow properties (shear stress-shear rate variation) of samples 2, 6, and 7.

\section{Conclusions}

Functional polycarboxylic acid high-performance superplasticizers function as a water-reducing and cement-dispersing agent to a certain extent. Different functional polycarboxylic acid high-performance water-reducing agents have various effects on the rheological and mechanical properties of cement pastes and mortars. Through the determination of rheological parameters such as shear yield stress, plastic viscosity, and fluidity, the functional polycarboxylic acid superplasticizers 
proved to have better water-reducing, cement dispersion, and slump retention features than the naphthalene-based superplasticizer. In terms of rheological and mechanical properties, the cement samples formulated with functional polycarboxylic acid water-reducing agents are more likely to achieve improved rheological properties and higher compressive strength than the cement-based materials containing naphthalene-based superplasticizers. Sustained-release functional polycarboxylic acid high-performance superplasticizer $\mathrm{H}$ gradually produces a water-reducing effect, which proves that it performs an excellent slump retention function. Early-strength functional polycarboxylic acid superplasticizer $Z$ can significantly enhance the early strength of cement paste and mortar.

The findings of the current work confirm that the functional groups available in the molecular structure of functional polycarboxylic acid superplasticizers play an important role in the performance of cement-based materials. Hence, a variety of functional polycarboxylic acid water-reducing agents can be designed to improve the quality of different types of cement and thus meet the requirements of various real engineering applications.

Author Contributions: Conceptualization, W.X. and Y.L.; methodology, W.X. and C.W.; experiment, W.X. and J.L.; data analysis, C.Y. and X.L.; validation, W.X. and D.X.; writing and original draft preparation, W.X.; writing, review, and editing, W.X. and J.L.; project administration, W.X. and Y.L.; funding acquisition, W.X. All authors have read and agreed to the published version of the manuscript.

Funding: This research was funded by the National Natural Science Foundation of China, grant number 2017YFB0307101.

Conflicts of Interest: The authors declare no conflict of interest.

\section{References}

1. Plank, J. Concrete Admixture and Its Application Technology; Machinery Industry Press: Beijing, China, 2004; pp. 13-27.

2. Urgessa, G.; Choi, K.B.; Yeon, J.H. Internal Relative Humidity, Autogenous Shrinkage, and Strength of Cement Mortar Modified with Superabsorbent Polymers. Polymers 2018, 10, 1074. [CrossRef] [PubMed]

3. Kim, D.; Kim, C.Y.; Urgessa, G.; Choi, J.H.; Park, C.; Yeon, J.H. Durability and Rheological Characteristics of High-volume Ground Granulated Blast-furnace Slag Concrete Containing CaCO3/anhydrate-based Alkali Activator. Constr. Build. Mater. 2019, 204, 10-19. [CrossRef]

4. Yamada, K.; Takahashi, T.; Hanehara, S.; Matsuhisa, M. Effects of the Chemical Structure on the Properties of Polycarboxylate-Type Superplasticizer. Cem. Concr. Res. 2000, 30, 197-207. [CrossRef]

5. Asghari, A.A.; Hernandez, A.M.L.; Feys, D.; De Schutter, G. Which parameters, other than the water content, influence the robustness of cement paste with SCC consistency. Constr. Build. Mater. 2016, 124, 95-103. [CrossRef]

6. Ma, B.; Ma, M.; Shen, X.; Li, X.; Wu, X. Compatibility between a polycarboxylate superplasticizer and the belite-rich sulfoaluminate cement: Setting time and the hydration properties. Constr. Build. Mater. 2014, 51, 47-54. [CrossRef]

7. Uchikawa, H.; Hanehara, S.; Sawaki, D. The role of steric repulsive force in the dispersion of cement particles in fresh paste prepared with organic admixture. Cem. Concr. Res. 1997, 27, 37-50. [CrossRef]

8. Kirby, G.H.; Lewis, J.A. Comb polymer architecture effects on the rheological property evolution of concentrated cement suspension. J. Am. Ceram Soc. 2004, 87, 1643-1652. [CrossRef]

9. Collepardi, M. Admixtures used to enhance placing characteristics of concrete. Cem. Concr. Compos. 1998, 20, 103-112. [CrossRef]

10. Jolicoer, C.; Simard, M.-A. Chemical admixture-cement interactions: Phenomenology and physico-chemical concepts. Cem. Concr. Compos. 1998, 20, 87-101. [CrossRef]

11. Struble, L.; Szecsy, R.; Lei, W.; Sun, G. Rheology of cement paste and concrete. Cem. Concr. Aggreg. 1998, 20, 269-277.

12. Zhang, Z.L.; Shi, H.X.; Sui, T.B. Effects of naphthalene-based superplasticizers on rheological properties of HBC and PC cement pastes. China Cem. 2003, 9, 55-58.

13. GolCaszewski, J.; Szwabowski, J. Influence of superplasticizers on rheological behavior of fresh cement mortars. Cem. Concr. Res. 2004, 34, 235-248. [CrossRef] 
14. Aiad, I. Influence of time addition of superplasticizers on the rheological properties of fresh cement pastes. Cem. Concr. Res. 2003, 33, 1229-1234. [CrossRef]

15. Ba, H.J.; Pan, Y.; Yang, Y.Z. Effects of fine mineral admixtures on rheological properties of high performance concrete. J. Harbin Jianzhu Univ. 2002, 12, 50-54.

16. Chandra, S.; Björnström, J. Influence of cement and superplasticizer type and dosage on the fluidity of cement mortars-Part I. Cem. Concr. Res. 2002, 32, 1605-1611. [CrossRef]

17. Mindes, S. Concrete; Chemical Industry Press: Beijing, China, 2005; pp. 156-162.

(C) 2020 by the authors. Licensee MDPI, Basel, Switzerland. This article is an open access article distributed under the terms and conditions of the Creative Commons Attribution (CC BY) license (http://creativecommons.org/licenses/by/4.0/). 